\title{
Modelo de diagnóstico e implementação de um sistema de gestão da qualidade: estudo de um caso
}

\author{
Luís Cláudio da Conceição Correia \\ Maria Auxiliadora do Nascimento Mélo \\ Denise Dumke de Medeiros \\ Universidade Federal de Pernambuco
}

\begin{abstract}
Resumo
Sabe-se que, devido ao aumento da competição nacional e internacional, muitas empresas estão implementando Sistemas de Gestão da Qualidade baseadas nos requisitos da norma ISO 9001:2000, como forma de se tornarem mais competitivas. Neste trabalho, propõe-se um modelo de diagnóstico e implementação adaptável a diferentes tipos de sistema de gestão da qualidade, segundo a necessidade da empresa, combinando três ambientes para gestão da qualidade: in-line, on-line e off-line. A partir desses ambientes, é apresentada uma aplicação prática do modelo para implementação da Norma ISO 9001:2000 em uma empresa do setor siderúrgico e os resultados alcançados.
\end{abstract}

Palavras-chave

Norma ISO 9001:2000, Sistema de Gestão da Qualidade, Qualidade in-line, Qualidade on-line, Qualidade off-line.

\section{Model to the diagnosis and implementation of a quality management system: a case study}

\begin{abstract}
It is known that due to the increase of the national and international competition, companies are implementing management quality systems based on the requirements of the international standard ISO 9001:2000 to become more competitive. In this work is proposed a diagnosis model to different types of quality system, according to the company's need, combining the in-line, on-line and off-line environment for quality management. In this way, it is presented a utilization of the model to implementation of the standard ISO 9001:2000 in a company of the metallurgical sector, as well as its results.
\end{abstract}

Key words

Standard ISO 9001:2000, Management Quality System, In-line Quality, On-line Quality, Off-line Quality. 


\section{INTRODUC̣ÃO}

A International Organization for Standardization ISO é uma organização internacional, com sede em Genebra, na Suíça, fundada em 1946, que tem como objetivo o desenvolvimento de normas técnicas para aplicação mundial, e sob a responsabilidade do Comitê Técnico TC 176 - Garantia da Qualidade - desenvolveu a primeira versão das normas da série ISO 9000 em 1987. Atualmente, após duas revisões da série, na versão de dezembro de 2000, essas normas ganharam importância à medida que aprofundaram a compreensão sobre diversas dimensões que impactam a gestão das organizações com foco na satisfação dos clientes (BRANSKY, 2004). Essas séries de normas representam o resultado do esforço de representantes de diversos países que buscaram interpretar e dar forma ao conceito de Sistema de Gestão da Qualidade.

- Liderança;

- Envolvimento de pessoas;

- Abordagem de processo;

- Abordagem sistêmica;

- Melhoria contínua;

- Abordagem factual para tomada de decisão;

- Parceria com os fornecedores.

Estes princípios também guiam os prêmios da qualidade: Prêmio Nacional da Qualidade (PNQ), Malcolm Baldrige National Quality Award (MBNQA) e European Business Excellence Model (BEM), permitindo que as organizações estruturem, planejem e desenvolvam seus esforços pela qualidade (LEONARD \& McADAM, 2003).

A versão das normas ISO 9000:2000 trouxe um novo enfoque aos elementos que compõem o Sistema de Gestão, enfatizando, por exemplo, a abordagem de processo visando tornar as organizações mais eficientes (BRANSKY, 2004).

Os requisitos da norma ISO 9004:2000 prevêem o mesmo modelo de processo (entrada - saída) e princípios de gestão da qualida-

As normas da série ISO 9000:2000 indicam a necessidade de se considerar as expectativas não só dos clientes, mas também de outras partes interessadas no negócio: os "stakeholders" (a sociedade, os clientes externos, os empregados, os fornecedores e os acionistas) (RODRIGUES, 2004). Esta série é composta pelas seguintes normas:

- ISO 9000:2000 - Sistema de Gestão da Qualidade Fundamentos e Vocabulários.

- ISO 9001:2000 - Sistema de Gestão da Qualidade Requisitos.

- ISO 9004:2000 - Sistema de Gestão da Qualidade Diretrizes para Melhoria de Desempenho.

Em particular, a norma ISO 9001 é utilizada quando a organização direciona os seus esforços para o aumento da satisfação dos clientes. Além disso, pode ser utilizada na demonstração de sua capacidade em fornecer produtos que atendam aos requisitos do cliente e aqueles regulamentares aplicáveis. Essa demonstração ocorre, por exemplo, quando, após a implementação dos requisitos e a avaliação da conformidade, a organização obtém a certificação do seu Sistema de Gestão (SMITH, 2002).

É importante observar que a formulação das três normas incorpora a necessidade de que a alta direção adote, em suas práticas de gestão, oito princípios na busca da melhoria do desempenho (CHAN, 1999):

- Foco no cliente; de, mas têm ênfase na satisfação das necessidades de todas as partes interessadas para atingir a satisfação do cliente (SMITH, 2002).

A gestão da qualidade envolve as ações de planejamento, de controle e de aprimoramento, a partir de políticas e objetivos estabelecidos pela direção. Requer organização e flexibilidade para poder servir como base de avaliação e aprimoramento contínuos dos produtos e processos envolvidos (LASZLO, 1998).

O Sistema da Qualidade, segundo as normas da série ISO 9000, tem seu foco na prevenção de não-conformidades, incluindo em seus requisitos a necessidade da adoção de práticas de correção das não-conformidades - NC, ações corretivas (para evitar a repetição das mesmas) e preventivas (para evitar a sua ocorrência) (CHAN, 1999).

De acordo com De Medeiros (2000), é possível diagnosticar um sistema da qualidade através de três fatoreschaves que são: a responsabilidade da administração, os recursos humanos e materiais e a estrutura do próprio sistema. Para a autora, a harmonia entre eles é uma condição necessária para a gestão da Qualidade nas empresas e, conseqüentemente, para satisfazer os clientes.

De acordo com Quazi (1997), muitas empresas têm escolhido a certificação pelas normas ISO 9000 um caminho até o Total Quality Management (TQM), o que seria um passo seguro e extremamente importante na busca das melhorias provenientes do TQM. 
Os oito princípios na busca da melhoria do desempenho estão inseridos, especificamente, nos requisitos da norma ISO 9004:2000 - Sistema de Gestão da Qualidade - Diretrizes para Melhoria de Desempenho - de maneira mais abrangente que na norma ISO 9001:2000 - Sistema de Gestão da Qualidade - Requisitos (ABNT, 2000).

Tomadas de decisão estratégicas podem ser feitas usando-se a linha do tempo para identificar seis estágioschaves para aplicação do sistema de qualidade numa empresa (como a implementação de novas iniciativas), de métodos ou de sistemas usados (como ISO 9000) e seu sucesso. Cada estágio é representado como um elemento do ciclo de vida da qualidade. São eles os seguintes: adoção (estágio de implementação de uma nova iniciativa de qualidade), regeneração (quando a nova iniciativa de qualidade está sendo usada em conjunto com outra já existente para gerar nova energia e impacto), energização (quando é dada à iniciativa de qualidade existente novo foco e recursos), maturação (quando a qualidade é estrategicamente alinhada e organizada dentro da empresa), limitação ou estagnação (quando a qualidade não tem sido estrategicamente alinhada e organizada dentro da empresa) e declínio (quando o sistema de gestão da qualidade não tem tido impacto, as iniciativas estão falhando e o sistema de gestão da qualidade está na expectativa de terminar) (LEONARD \& McADAM, 2003).

$\mathrm{O}$ ciclo de vida da qualidade é representado por um conjunto de ferramentas estratégicas e dinâmicas que reconhecem que a qualidade está continuamente mudando, ela é complexa e não pode ser facilmente representada de uma maneira seqüencial ou linear como um modelo corrente. O ciclo de vida da qualidade pode representar diferentes aspectos da gestão da qualidade, inclusive iniciativas como ISO 9000 (LEONARD \& McADAM, 2003).

Portanto, cada organização deve decidir qual o modelo adequado a ser utilizado e quais os requisitos aplicáveis ao seu Sistema da Qualidade. Essa decisão deve ser tomada levando-se em consideração o tipo de negócio, o produto, o processo e o risco envolvido. Não é obrigatória a aplicação de todos os requisitos do modelo escolhido, mas a organização precisa justificar a não aplicabilidade de qualquer requisito, em caso da busca pela certificação.

\section{PROBLEMÁTICA E OBJETIVOS}

Um dos principais fatores que dificultam a implementação de um Sistema de Gestão da Qualidade (SGQ) por parte das pequenas e médias empresas é a falta de um diagnóstico de implementação desse sistema.

Não conhecer o quanto deve ser melhorado no sistema de gestão da empresa para a implementação do SGQ pode também dificultar e atrasar a implementação efetiva do sistema. Assim, esse trabalho de pesquisa teve como objetivo tentar esclarecer, mensurar e equacionar os itens da norma ISO 9001:2000 a serem implementados pelas empresas adaptando para o ambiente da qualidade (online, in-line ou off-line) que seja predominante na sua estrutura, para, dessa forma, auxiliar as pequenas e médias empresas que almejam implementar um Sistema de Gestão da Qualidade.

\section{I fator que dificulta a implementação do SGQ nas empresas é a falta de diagnóstico inicial deste sistema.}

Os objetivos específicos desse trabalho voltados para a melhoria da inserção do SGQ numa empresa são:

1. dar diretrizes para implementar a Norma ISO 9001:2000, ou para executar a transição de uma outra norma para a ISO 9001:2000;

2. elaborar um modelo de diagnóstico do SGQ de uma empresa;

3. fornecer um guia para a implementação.

A metodologia usada nesse trabalho foi descritiva e exploratória. A pesquisa descritiva objetivou conhecer e interpretar a realidade sem nela interferir para modificála (BARROS \& LEHFELD, 1990). Com isso, foi possível expor as características de determinada população ou de determinado fenômeno, sem o compromisso de explicar os fenômenos descritos, embora pode servir de base para tal explicação.

A pesquisa exploratória visa proporcionar ao pesquisador uma maior familiaridade com o problema em estudo. Este tipo de pesquisa é adotada em casos nos quais é necessário definir o problema com maior precisão e identificar cursos relevantes de ação ou obter dados adicionais antes que se possa desenvolver uma abordagem. Como o nome sugere, a pesquisa exploratória procura explorar um problema ou uma situação para prover critérios e compreensão (BARROS \& LEHFELD, 1990).

A pesquisa exploratória utiliza métodos bastante amplos e versáteis. Os métodos empregados compreendem: levantamentos em fontes secundárias (bibliográficas, documentais, etc.), levantamentos de experiência, estudos de casos selecionados e observação informal (direta 
e indireta), os quais foram utilizados neste trabalho. Também foi realizada a aplicação do modelo proposto em uma empresa siderúrgica, procurando mostrar os aspectos relativos à implementação do conjunto de requisitos da Norma ISO 9001:2000 na empresa estudada.

\section{MODELO DE DIAGNÓSTICO PARA ANÁLISE DA IMPLEMENTAC̄ÃO DE UM SISTEMA DE GESTÃO DA QUALIDADE}

A seguir, será apresentado o modelo proposto para avaliação, que serve como guia para a implementação do Sistema de Gestão da Qualidade baseado nos requisitos da Norma ISO 9001:2000, dividido em duas partes. Na primeira parte, foi realizada uma análise comparativa entre os diferentes tipos de empresa e os graus de dificuldade para a implementação dos requisitos da Norma ISO 9001:2000. As empresas foram agrupadas em cinco categorias, estabelecidas a partir da definição de Paladini (2002) acerca dos ambientes da qualidade on-line, qualidade off-line e qualidade in-line, que serão apresentados adiante.

$\mathrm{Na}$ segunda parte, foi descrito um modelo para diagnóstico do SGQ que pode avaliar, de forma quantitativa, o percentual de implementação dos requisitos da Norma ISO 9001:2000. Finalmente, será apresentado um estudo de um caso em uma empresa do setor siderúrgico, que estava passando pelo processo de mudança em seu SGQ em decorrência da mudança da certificação ISO 9001:1994 para o modelo 2000.

\section{Modelo Comparativo entre Empresas com Diferentes Sistemas de Gestão da Qualidade}

A dificuldade de implementação de alguns requisitos da norma ISO 9000:2000 depende do tipo de empresa que está almejando esse objetivo, pois algumas delas terão maior dificuldade na implementação de alguns requisitos da norma do que outras empresas para os mesmos requisitos. Isso se deve ao fato de que, devido ao tipo de empresa e ambiente da qualidade predominante, alguns requisitos serão mais fáceis do que outros para implementar. Por isso, foi desenvolvida a classificação descrita a seguir.
Para Paladini (2002), existem três ambientes da qualidade: on-line, off-line e in-line. Esses ambientes serviram de base para a classificação das empresas em cinco categorias distintas proposta neste trabalho.

A qualidade in-line é um ambiente da qualidade voltado para a área produtiva, o enfoque desse ambiente é no produto, para que ele esteja adequado ao uso, ou seja, na ausência total de não-conformidades. Nesse ambiente, é comum as empresas adotarem campanhas de redução de horas extras, redução de custos, eliminação de desperdícios, etc.

A qualidade off-line foi definida como a qualidade proporcionada por áreas de apoio às áreas produtivas, as que não estão ligadas diretamente ao setor produtivo, porém, sendo de extrema importância para que o produto final atenda às necessidades dos clientes, como por exemplo a aquisição de matéria-prima, vendas, marketing, projeto e pessoal.

$\mathrm{O}$ ambiente da qualidade on-line concentra-se na busca de informações das possíveis alterações do mercado, hábitos de consumo, comportamento, entre outras, a fim de que essas informações sejam repassadas aos departamentos de projeto ou diretamente à área de produção.

Há empresas onde o modelo in-line é o mais adequado para descrevê-las em relação à qualidade, principalmente aquelas que fabricam produtos do tipo commodity, cujas características físicas são muito semelhantes às das empresas concorrentes. Também existem empresas que combinam todos os ambientes da qualidade.

Nesse trabalho, propõe-se determinar cinco tipos de empresas que terão os três ambientes da qualidade definidos acima e divididos em cinco categorias. As categorias são, A, B, C, D e E. A Tabela 1 a seguir demonstra, resumidamente, a classificação das empresas em função dos modelos de qualidade on-line, off-line e in-line.

As empresas do tipo A são empresas de produção de bens do tipo commodity, como por exemplo siderúrgicas e refinarias de açúcar e óleo, que têm uma relação muito estreita com a qualidade in-line, pois a ênfase é a melhoria do processo produtivo. As empresas dessa categoria fazem campanhas para a redução dos custos de produção, dado que o seu produto tem as mesmas características

Tabela 1: Relação entre tipos de empresas e modelo de qualidade.

\begin{tabular}{|c|c|c|c|}
\hline TIPO DE EMPRESA & QUALIDADE IW-LINE & QUALIDADE OFF-LINE & QUALIDADE ON-LINE \\
\hline $\mathrm{A}$ & $\mathrm{X}$ & & \\
\hline $\mathrm{B}$ & $\mathrm{X}$ & $\mathrm{X}$ & $\mathrm{X}$ \\
\hline $\mathrm{C}$ & $\mathrm{X}$ & $\mathrm{X}$ & $\mathrm{X}$ \\
\hline $\mathrm{D}$ & & $\mathrm{X}$ & $\mathrm{X}$ \\
\hline $\mathrm{E}$ & & & \\
\hline
\end{tabular}


dos concorrentes. Uma forma de se destacar das demais seria a oferta de um produto de menor custo. Os produtos dessas empresas geralmente sofrem poucas alterações das suas características de qualidade e, dessa forma, são poucas as inovações.

As empresas do tipo B são aquelas que produzem bens, mas que precisam estar constantemente inovando ou criando novos produtos para atender, ou mesmo superar as expectativas dos clientes. As empresas que fabricam e vendem computadores compõem um exemplo, pois o ciclo de vida de um computador é pequeno e a renovação tecnológica é muito freqüente. Essas empresas precisam freqüentemente inovar, consultar o mercado e manter uma boa equipe de desenvolvimento de forma que seja possível manterem-se competitivas.

Se forem empresas competitivas, terão dois modelos de qualidade presentes simultaneamente no sistema de qualidade, que são: Qualidade in-line e Qualidade off-line. Elas precisam manter um relacionamento estreito com o mercado, inovar, ter flexibilidade na produção e um bom sistema de informação com uma boa sistemática nas áreas de apoio bem como na área produtiva.

As empresas do tipo $\mathrm{C}$ são as que fabricam produtos que atendem às necessidades dos clientes e solucionam seus problemas. Para solucioná-los precisam ser empresas muito dinâmicas e com ciclo feed-back e resposta muito rápida, como exemplo são as empresas que produzem softwares, entre outras. Empresas desse tipo adotam os três modelos de qualidade.

As empresas do tipo D são aquelas que prestam serviços e, apesar do contato com o cliente final ser constante, não mudam com freqüência o seu tipo de serviço. São empresas como lavanderias, entre outras. Essas empresas utilizam o modelo off-line com maior ênfase.

Finalmente, as empresas do tipo E são aquelas que prestam serviços como produto final, porém precisam constantemente alterar seu produto para tornarem-se competitivas e, dessa forma, não desaparecerem do mercado. São empresas como decoração e design, entre outras, que se utilizam freqüentemente dos modelos off-line e on-line.

Para que seja feita a comparação entre os requisitos da norma com o grau de dificuldade para sua implementação, são feitas algumas considerações. Inicialmente, é importante relembrar que foram considerados todos os requisitos da Norma ISO 9001:2000. Na tabela comparativa apresentada a seguir, além dos principais requisitos da norma ISO 9001:2000, há alguns subitens que foram levados em consideração devido à sua importância.

Assim, há no total 22 requisitos e subitens na tabela, onde foram dados valores que podem variar entre 1 (um) e 22 ( vinte e dois), o que significa dizer que nessa escala o valor 1 é o item/subitem mais fácil a ser implementado e que o valor 22 é o item/sub-item mais difícil para ser implementado naquele tipo de empresa. Essa numeração é uma ordenação dos requisitos, ou seja, é um guia de quais itens poderiam ser priorizados na implementação, levando em consideração os recursos disponíveis.

É possível que, para um mesmo tipo de empresa, dois ou mais itens/subitens diferentes tenham o mesmo grau de dificuldade e, dessa forma, podem ter a mesma pontuação. Quando ocorrer um item/subitem com valor 1 e um outro com valor 4 , isso não significa dizer que o item/subitem com valor 4 seja quatro vezes mais difícil de ser implementado.

\section{$\triangle$ dificuldade de implementação dos requisitos da norma ISO 9000:2000 do tipo de empresa.}

Os requisitos/tópicos das tabelas não estão desdobrados, porque a idéia é que seja feita uma análise de como seria a implementação geral do requisito, levando em consideração todos os seus componentes.

Estão apresentadas na Tabela 2 essas relações.

\section{Apresentação do Modelo de Diagnóstico para Avaliação da Implementação dos Requisitos da Norma ISO 9001:2000}

O objetivo principal para a elaboração do Modelo de Diagnóstico para a Avaliação da Implementação dos Requisitos da Norma ISO 9001:2000 é a organização dos tópicos mais abrangentes: Requisitos de documentação, Comprometimento da alta administração, Análise crítica pela alta administração, Provisão de recursos, Recursos humanos, Infra-estrutura, Processos relacionados aos clientes/Foco no cliente, Realização do produto, Projeto e desenvolvimento, Aquisição, Produção e fornecimento de serviço, Controle de dispositivos de medição e monitoramento, Controle de produtos não-conforme, Análise de dados e medição, Análise, Melhoria/monitoramento.

O diagnóstico foi elaborado com o propósito de ser simples e objetivo. Dessa forma, os requisitos da norma ISO 9001:2000 foram agrupados em cinco grandes grupos e divididos em subitens. Foi criada uma escala onde o valor 0 indica que não há nenhuma evidência de implementação do requisito e o valor 5 indica que o requisito está implementado, documentado e disseminado pelas áreas de interesse. A seguir é dado o descritivo de cada valor utilizado na pesquisa. Os valores seguem a seguinte classificação: 
0- Não há nenhuma evidência de implementação do item;

1- Não está documentado e não está completamente disseminado pelas áreas de interesse;

2- Documentado, mas não está disseminado pelas áreas de interesse;

3- Não está documentado, mas está disseminado pelas áreas de interesse;

4- Documentado, mas não está completamente disseminado pelas áreas de interesse;

5- Documentado e disseminado pelas áreas de interesse.

O questionário desenvolvido para o diagnóstico é composto de três colunas: a primeira coluna mostra a faixa que varia de 0 a 5 e serve para indicar o grau de implementação dos requisitos na empresa. A segunda coluna receberá o valor da avaliação e na sua última linha deve ser colocado o somatório das avaliações, há o valor total que o requisito avaliado pode receber. A terceira coluna é uma descrição do item que está sendo avaliado. É importante relembrar que o SGQ deve ser considerado como implementado quando o diagnóstico for igual a $100 \%$.

$\mathrm{Na}$ Tabela 3, será apresentado um exemplo de como o diagnóstico pode ser utilizado. Se uma empresa quer avaliar, ou seja, gostaria de saber quanto dos requisitos da norma ISO 9001:2000 está implementado, ela pode utilizar os questionamentos do diagnóstico. A empresa poderá fazer uma avaliação sucinta do seu sistema de gestão da qualidade.

Este exemplo ilustrativo refere-se à avaliação do requisito de documentação. Observa-se, por esta tabela, que foi obtido um total de 24 na avaliação da implementação onde a pontuação máxima seria 30 . Assim, pode-se observar que $(24 / 30) * 100=80 \%$ de implementação, ou seja, a empresa avaliada tem $80 \%$ dos requisitos de documentação implementados.

$\mathrm{Na}$ Tabela 4, são apresentados alguns exemplos dos itens para diagnóstico do Sistema de Gestão da Qualidade previstos pelos requisitos da norma ISO 9001:2000. A lista completa está apresentada mais adiante, no estudo de um caso apresentado no tópico seguinte.

Tabela 2: Relação entre tipos de empresas e o grau de dificuldade de implementação dos itens da norma.

\begin{tabular}{|c|c|c|c|c|c|}
\hline \multirow{2}{*}{ REQUISITOS DA NORMA ISO 9001:2000 } & \multicolumn{5}{|c|}{ TIPO DE EMPRESA } \\
\hline & $\mathbf{A}$ & $\mathbf{B}$ & C & D & $E$ \\
\hline Requisitos de documentação & 6 & 10 & 11 & 5 & 12 \\
\hline Responsabilidade da Administração & 11 & 9 & 11 & 6 & 12 \\
\hline Comprometimento da Administração & 12 & 2 & 2 & 7 & 11 \\
\hline Foco no cliente & 20 & 1 & 4 & 11 & 1 \\
\hline Política da qualidade & 10 & 4 & 3 & 8 & 3 \\
\hline Planejamento & 20 & 6 & 1 & 10 & 14 \\
\hline Análise crítica pela administração & 13 & 7 & 9 & 9 & 15 \\
\hline Gestão de recursos & 14 & 11 & 3 & 12 & 4 \\
\hline Infra-estrutura & 17 & 16 & 6 & 20 & 21 \\
\hline Ambiente de trabalho & 15 & 5 & 13 & 22 & 16 \\
\hline Planejamento da realização do produto & 19 & 8 & 1 & 13 & 17 \\
\hline Processos relacionados ao cliente & 22 & 3 & 15 & 4 & 8 \\
\hline Projeto e desenvolvimento & 18 & 12 & 5 & 14 & 9 \\
\hline Aquisição & 5 & 13 & 9 & 22 & 18 \\
\hline Produção e fornecimento de serviço & 15 & 10 & 15 & 1 & 2 \\
\hline Controle de dispositivos de medição e monitoramento & 1 & 15 & 17 & 20 & 19 \\
\hline Medição e monitoramento & 2 & 16 & 18 & 19 & 20 \\
\hline Controle de produto não-conforme & 3 & 4 & 9 & 2 & 9 \\
\hline Análise de dados & 4 & 14 & 22 & 3 & 22 \\
\hline Melhoria contínua & 9 & 3 & 5 & 15 & 5 \\
\hline Ações corretivas & 8 & 6 & 7 & 17 & 7 \\
\hline Ações preventivas & 7 & 5 & 7 & 16 & 6 \\
\hline
\end{tabular}


Tabela 3: Exemplo de avaliação de requisitos.

\begin{tabular}{|c|c|l|}
\hline FAIXA & VALOR & \multicolumn{1}{|c|}{ REQUISITOS } \\
\hline $0-5$ & $\mathbf{3 0}$ & Requisitos de documentação \\
\hline $0-5$ & ( 5 ) & Declaração da política da qualidade documentada juntamente com os objetivos \\
\hline $0-5$ & ( 3 ) & Declaração dos objetivos qualidade \\
\hline $0-5$ & ( 5) & Procedimentos documentados \\
\hline $0-5$ & $(4)$ & Requisitos da qualidade \\
\hline $0-5$ & $(3)$ & Pessoas envolvidas no SGQ treinadas \\
\hline Total & $\mathbf{2 4}$ & \\
\hline
\end{tabular}

Tabela 4: Diagnóstico de implementação dos itens da norma ISO 9001:2000.

\begin{tabular}{|c|c|c|}
\hline FAIXA & VALOR & REQUISITOS \\
\hline & 30 & Requisitos de documentação \\
\hline $0-5$ & ( ) & Declaração da política da qualidade documentada juntamente com os objetivos \\
\hline $0-5$ & ( ) & Declaração dos objetivos da qualidade \\
\hline $0-5$ & ( ) ] & 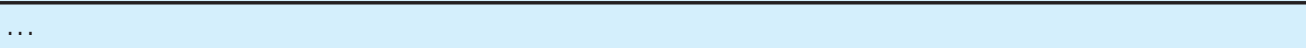 \\
\hline \multicolumn{3}{|l|}{ Total } \\
\hline & 25 & Comprometimento da administração \\
\hline $0-5$ & ( ) & Comunicação dos itens e metas da organização \\
\hline $0-5$ & $($ ) & Instituição da política da qualidade \\
\hline $0-5$ & ( ) & $\ldots$ \\
\hline \multicolumn{3}{|l|}{ Total } \\
\hline & 25 & Política da qualidade \\
\hline $0-5$ & ( ) & Apropriada aos propósitos da empresa \\
\hline $0-5$ & ( ) & Comprometimento com a melhoria contínua \\
\hline $0-5$ & ( ) & $\ldots$ \\
\hline \multicolumn{3}{|l|}{ Total } \\
\hline & 30 & Responsabilidade, autoridade e comunicação \\
\hline $0-5$ & ( ) & Ter representante formal da alta administração para o SGQ \\
\hline $0-5$ & ( ) ] & O representante deve assegurar que os processos necessários p/ o SGQ são mantidos \\
\hline $0-5$ & ( ) & $\ldots$ \\
\hline \multicolumn{3}{|l|}{ Total } \\
\hline & 55 & Análise crítica pela alta administração \\
\hline $0-5$ & $(\mathrm{l})$ & Ter resultados de auditoria como entrada \\
\hline $0-5$ & ( ) & Ter realimentação do cliente como entrada \\
\hline $0-5$ & ( ) & $\ldots$ \\
\hline \multicolumn{3}{|l|}{ Total } \\
\hline & 20 & Provisáo de recursos \\
\hline $0-5$ & {$[$ ] } & Provisão de recursos para implementar. \\
\hline $0-5$ & ( ) & Provisão de recursos para manter o SGQ. \\
\hline $0-5$ & ( ) & $\ldots$ \\
\hline \multicolumn{3}{|l|}{ Total } \\
\hline & 15 & Recursos humanos \\
\hline $0-5$ & {$[$ ] } & Determinação das competências necessárias para o pessoal que executa trabalhos que afetam a qualidade do produto. \\
\hline $0-5$ & $(\mathrm{l})$ & Comprovação do fornecimento de treinamento. \\
\hline $0-5$ & ( ) & $\ldots$ \\
\hline Total & & \\
\hline
\end{tabular}




\begin{tabular}{|c|c|c|}
\hline FAIXA & VALOR & REQUISITOS \\
\hline & 15 & Infra-estrutura \\
\hline $0-5$ & $(\mathrm{l})$ & Ter edifícios, espaço de trabalho, instalações associadas \\
\hline $0-5$ & ( ) & Ter equipamentos de processo \\
\hline $0-5$ & {$[\quad]$} & $\ldots$ \\
\hline \multicolumn{3}{|l|}{ Total } \\
\hline & 55 & Processos relacionados aos clientes / foco no cliente \\
\hline $0-5$ & $(\mathrm{l})$ & Determinação dos requisitos especificados pelo cliente \\
\hline $0-5$ & $(\mathrm{l})$ & Determinação dos requisitos especificados pela entrega \\
\hline $0-5$ & $(\mathrm{l})$ & $\ldots$ \\
\hline \multicolumn{3}{|l|}{ Total } \\
\hline & 140 & Projeto e desenvolvimento de produto/ Planejamento da realizaçáo do produto \\
\hline $0-5$ & $(\mathrm{l})$ & Determinar os estágios do projeto e desenvolvimento \\
\hline $0-5$ & ( ) & Determinar a análise crítica em cada fase do projeto \\
\hline $0-5$ & ( ) & $\ldots$ \\
\hline \multicolumn{3}{|l|}{ Total } \\
\hline & 45 & Aquisição \\
\hline $0-5$ & ( ) & Procedimento de aquisição de produto \\
\hline $0-5$ & $(\mathrm{l})$ & Avaliação de fornecedores \\
\hline $0-5$ & ( ) & $\ldots$ \\
\hline \multicolumn{3}{|l|}{ Total } \\
\hline & 45 & Produção e fornecimento de serviço \\
\hline $0-5$ & $(\mathrm{l})$ & Incluir a disponibilidade de informações que descrevem as características do produto \\
\hline $0-5$ & $(\mathrm{l})$ & Incluir a disponibilidade de instrução de trabalho \\
\hline $0-5$ & $(\mathrm{l})$ & $\ldots$ \\
\hline \multicolumn{3}{|l|}{ Total } \\
\hline & 25 & Controle de dispositivos de medição e monitoramento \\
\hline $0-5$ & $(1)$ & $\begin{array}{l}\text { Os dispositivos devem ser calibrados ou verificados em intervalos específicos antes do uso, contra padrões de } \\
\text { medição rastreáveis }\end{array}$ \\
\hline $0-5$ & $(\mathrm{l})$ & Os dispositivos devem ser ajustados e reajustados, como necessários \\
\hline $0-5$ & ( ) & $\ldots$ \\
\hline \multicolumn{3}{|l|}{ Total } \\
\hline & 20 & Controle de produto não-conforme \\
\hline $0-5$ & $(\mathrm{l})$ & Assegurar a tomada de ações para eliminar a não-conformes detectada \\
\hline $0-5$ & {$[$ ] } & Assegurar a autorização do seu uso \\
\hline $0-5$ & ( ) & .. \\
\hline \multicolumn{3}{|l|}{ Total } \\
\hline & 20 & Análise de dados \\
\hline $0-5$ & ( ) & Deve-se ter informação da satisfação do cliente \\
\hline $0-5$ & {$[$ ] } & Deve-se ter informação com os requisitos do produto \\
\hline $0-5$ & ( ) & $\ldots$ \\
\hline \multicolumn{3}{|l|}{ Total } \\
\hline & 80 & Medição, análise e melhoria / Monitoramento \\
\hline $0-5$ & ( ) & Procedimento para análise crítica das não-conformidades \\
\hline $0-5$ & ( ) ] & Procedimento de determinação das causas das não-conformidades \\
\hline $0-5$ & $(\mathrm{l})$ & $\ldots$ \\
\hline Total & & \\
\hline
\end{tabular}


É importante salientar que, para a implementação do modelo, é necessário que o gerente da qualidade reúna os responsáveis pela aplicação dos requisitos da norma ISO 9001:2000 em cada setor e discuta com eles o valor a ser dado na classificação de cada item requerido na norma. Assim, em algumas empresas, isto poderá ser feito rapidamente, principalmente naquelas que já possuem um SGQ implementado e documentado. Em outras empresas, este processo de avaliação exigirá um tempo de dedicação maior considerando que os responsáveis envolvidos não estejam tão familiarizados com os requisitos da norma ISO 9001:2000.

O porte, o tipo de processo de produção e a competência dos recursos humanos da empresa são exemplos de outras variáveis que interferem na implementação do diagnóstico proposto, visto que, por exemplo, a complexidade da documentação em empresas de grande porte poderá requerer um período de tempo mais extenso na análise do cumprimento dos requisitos.

Assim, não há uma maneira única de implementar o modelo de diagnóstico proposto neste trabalho, como também não há uma só forma de implementar os requisitos da norma ISO 9001:2000, visto que fatores como a cultura da empresa, seus valores, os recursos humanos que a compõem fazem com que cada implementação seja baseada em princípios próprios de cada empresa, levando em consideração suas habilidades, competências, experiências, disponibilidade de recursos e os motivos que a levaram a buscar a certificação.

\section{ESTUDO DE UM CASO}

O modelo para diagnóstico proposto por este trabalho foi utilizado em uma empresa do setor siderúrgico, para avaliar o seu Sistema de Gestão da Qualidade a fim de que, desse modo, pudesse ser verificada a possibilidade da passagem do modelo atual para o modelo do Sistema de Gestão da Qualidade baseado nos requisitos da norma ISO 9001:2000.

Essa empresa estava certificada há dois anos pela NBR 7480, e utilizava o SGQ baseado nos requisitos da norma ISO 9001:1994 e tinha planos para a certificação segundo a norma ISO 9001:2000. Assim, a empresa gostaria de uma avaliação detalhada para que seus recursos disponíveis fossem utilizados nos requisitos mais importantes.

O primeiro passo para a avaliação era definir a que tipo de empresa ela pertence, baseando-se nos ambientes de qualidade in-line, on-line e off-line. Assim, definiu-se que esta empresa é do tipo A, visto que seu produto principal é o aço e o foco da empresa é a melhoria do processo produtivo. A partir de seu modelo da qualidade in-line predominante, chegou-se à seguinte ordenação por grau de dificuldade de implementação dos itens da norma ISO 9001:2000.

\section{a avaliação, deve-se inicialmente de empresa baseando-se nos alidade in-line, on-line e off-line.}

O primeiro requisito com valor 1 será o mais fácil de implementar e, assim, vai requerer menos recursos, em contrapartida, o último item (com valor 22) será o mais difícil de implementar e provavelmente precisará de mais recursos para a sua implementação, como apresentado na Tabela 2. O segundo passo adotado foi a aplicação do diagnóstico, que segue na Tabela 5. A decisão sobre a pontuação na empresa foi feita em equipe, pelos responsáveis pela certificação em cada setor da empresa, junto com o responsável pela Qualidade, designado pela diretoria.

\section{Resultados do Diagnóstico}

A seguir, serão apresentados, individualmente, por requisito, os resultados da aplicação do diagnóstico e implementação dos requisitos da norma ISO 9001:2000, verificados na empresa do setor siderúrgico.

No modelo proposto, considera-se uma empresa com todo o SGQ implementado quando o diagnóstico for igual a $100 \%$. Todos os requisitos foram calculados da seguinte maneira, tomando como exemplo o requisito "Comprometimento da administração", que tem um total de 25 pontos e que pela Tabela 5 obteve um total de 18 pontos na avaliação da implementação. Assim, observa-se que a empresa tem $72 \%$ do requisito "Comprometimento da administração" implementado, pois percentualmente tem-se $(\boldsymbol{\%})$ de implementação $=(\mathbf{1 8} /$ $25) * 100=72 \%$.

Nos valores apresentados na Tabela 5, pode-se observar que os seguintes requisitos estão completamente documentados e disseminados pela empresa, visto que receberam valor 5 em todos seus subitens, e por isso obtiveram a percentagem de implementação de 100,0\%: "Requisitos de documentação", "Infra-estrutura", "Controle de dispositivos de medição e monitoramento" e "Controle de produto não-conforme".

O requisito "Comprometimento da administração" obteve $72 \%$ de implementação. Pela análise da Tabela 5, 
Tabela 5: Diagnóstico de Implementação dos Requisitos da norma ISO 9001:2000 em uma Siderúrgica.

\begin{tabular}{|c|c|c|}
\hline FAIXA & VALOR & REQUISITOS \\
\hline & 30 & Requisitos de documentação \\
\hline $0-5$ & $(5)$ & Declaração da política da qualidade documentada juntamente com os objetivos \\
\hline $0-5$ & $(5)$ & Declaração dos objetivos da qualidade \\
\hline $0-5$ & $(5)$ & Manual da qualidade abrangendo os requisitos da norma \\
\hline $0-5$ & $(5)$ & Procedimentos documentados \\
\hline $0-5$ & $(5)$ & Registros da qualidade \\
\hline $0-5$ & ( 5 ) & Registro de treinamento de pessoas envolvidas no SGQ \\
\hline \multirow[t]{2}{*}{ Total } & 30 & \\
\hline & 25 & Comprometimento da administração \\
\hline $0-5$ & ( 4 ) & Comunicação dos itens e metas da organização \\
\hline $0-5$ & (5) & Instituição da política da qualidade \\
\hline $0-5$ & $(2)$ & Instituição dos objetivos da qualidade \\
\hline $0-5$ & ( 4 ) & Condução da análise crítica \\
\hline $0-5$ & ( 3 ) & Disponibilização de recursos para o SGQ no planejamento da empresa \\
\hline \multirow[t]{2}{*}{ Total } & 18 & \\
\hline & 25 & Política da qualidade \\
\hline $0-5$ & $(5)$ & Apropriada aos propósitos da empresa \\
\hline $0-5$ & $(0)$ & Comprometimento com a melhoria contínua \\
\hline $0-5$ & $(0)$ & Estrutura para instituição e análise dos objetivos da qualidade \\
\hline $0-5$ & ( 5 ) & Comunicada e entendida por toda a organização \\
\hline $0-5$ & {$[0]$} & Analisada criticamente para ser mantida e melhorada \\
\hline \multirow[t]{2}{*}{ Total } & 10 & \\
\hline & 30 & Responsabilidade, autoridade e comunicação \\
\hline $0-5$ & ( 5 ) & Ter representante formal da alta administração para o SGQ \\
\hline $0-5$ & (5) & O representante deve assegurar que os processos necessários p/ o SGQ são mantidos \\
\hline $0-5$ & $(4)$ & O representante deve assegurar que os processos necessários p/ o SGQ são instituídos \\
\hline $0-5$ & $(0)$ & O representante deve assegurar que os processos necessários p/ o SGQ são melhorados \\
\hline $0-5$ & ( 5 ) & O responsável deve relatar à alta administração o desempenho do SGQ \\
\hline $0-5$ & ( 3 ) & Ter canais de comunicação \\
\hline \multirow[t]{2}{*}{ Total } & 22 & \\
\hline & 55 & Análise crítica pela alta administração \\
\hline $0-5$ & ( 5 ] & Ter resultados de auditoria como entrada \\
\hline $0-5$ & $(0)$ & Ter realimentação do cliente como entrada \\
\hline $0-5$ & $(0)$ & Ter o desempenho do processo como entrada \\
\hline $0-5$ & ( 5 ) & Ter conformidade dos produtos como entrada \\
\hline $0-5$ & ( 0$)^{2}$ & Ter o acompanhamento das ações preventivas \\
\hline $0-5$ & ( 3 ) & Ter o acompanhamento das ações corretivas \\
\hline $0-5$ & (0) & Ter planejado as mudanças que possam afetar o SGQ \\
\hline $0-5$ & ( 3 ) & Evidenciar as melhorias do produto em relação aos requisitos dos clientes \\
\hline $0-5$ & $(5)$ & Evidências da implementação do SGQ \\
\hline $0-5$ & ( 5 ) & Evidências da manutenção do SGQ \\
\hline $0-5$ & ( 3 ] & Evidenciar melhorias do SGQ \\
\hline Total & 29 & \\
\hline
\end{tabular}




\begin{tabular}{|c|c|c|}
\hline FAIXA & VALOR & REQUISITOS \\
\hline & 20 & Provisão de recursos \\
\hline $0-5$ & $(5)$ & Provisão de recursos para implementar \\
\hline $0-5$ & $(0)$ & Provisão de recursos para manter o SGQ \\
\hline $0-5$ & $(0)$ & Provisão de recursos para melhorar o SGQ \\
\hline $0-5$ & (4) & Provisão de recursos para o aumento da satisfação dos clientes \\
\hline \multirow[t]{2}{*}{ Total } & 09 & \\
\hline & 15 & Recursos humanos \\
\hline $0-5$ & ( 3 ) & Determinação das competências necessárias para o pessoal que executa trabalho que afeta a qualidade do produto \\
\hline $0-5$ & $(5)$ & Comprovação do fornecimento de treinamento \\
\hline $0-5$ & $(0)$ & Verificação da eficácia dos treinamentos \\
\hline \multirow[t]{2}{*}{ Total } & 08 & \\
\hline & 15 & Infra-estrutura \\
\hline $0-5$ & $(5)$ & Ter edifícios, espaço de trabalho, instalações associadas \\
\hline $0-5$ & $(5)$ & Ter equipamentos de processo \\
\hline $0-5$ & ( 5 ) & Ter serviço de apoio, como transporte ou comunicação \\
\hline \multirow[t]{2}{*}{ Total } & 15 & \\
\hline & 55 & Processos relacionados aos clientes/foco no cliente \\
\hline $0-5$ & $(5)$ & Determinação dos requisitos especificados pelo cliente \\
\hline $0-5$ & (5) & Determinação dos requisitos especificados pela entrega \\
\hline $0-5$ & $(0)$ & Determinação dos requisitos especificados de atividades de pró-entrega \\
\hline $0-5$ & ( 3 ) & Determinação dos requisitos não declarados pelo cliente, mas necessários para o uso especificado \\
\hline $0-5$ & $(5)$ & Determinação dos requisitos estatutários e regulamentos relacionados ao produto \\
\hline $0-5$ & $(5)$ & Requisitos do produto definidos \\
\hline $0-5$ & $(5)$ & Assegurados os requisitos do contrato ou de pedido que defiram daqueles previamente manifestados estão resolvidos \\
\hline $0-5$ & $(5)$ & Assegurado que a organização tem capacidade para atender os requisitos especificados \\
\hline $0-5$ & $(5)$ & Comunicação com os clientes com relação ao produto \\
\hline $0-5$ & ( 3 ) & Comunicação com os clientes com relação a tratamento de indagações, contratos ou pedidos, incluindo complementos \\
\hline $0-5$ & $(5)$ & Comunicação com os clientes com relação a realimentação, incluindo reclamações \\
\hline \multirow[t]{2}{*}{ Total } & 46 & \\
\hline & 40 & Projeto e desenvolvimento de produto / Planejamento da realização do produto \\
\hline $0-5$ & $(5)$ & Determinar requisitos para o produto \\
\hline $0-5$ & $(5)$ & Determinar a necessidade para instituir processos e documentos e prover recursos específicos para o produto \\
\hline $0-5$ & $(5)$ & Determinar a verificação do produto \\
\hline $0-5$ & $(5)$ & Determinar a validação do produto \\
\hline $0-5$ & ( 5 ) & Determinar o monitoramento do produto \\
\hline $0-5$ & ( 1 ) & Objetivos da qualidade mensuráveis e consistentes com a política \\
\hline $0-5$ & ( 3 ) & Planejamento da qualidade de acordo com os requisitos \\
\hline $0-5$ & $(0)$ & Planejamento de novos processos \\
\hline \multirow[t]{2}{*}{ Total } & 29 & \\
\hline & 45 & Aquisição \\
\hline $0-5$ & $(5)$ & Procedimento de aquisição de produto \\
\hline $0-5$ & $(5)$ & Avaliação de fornecedores \\
\hline $0-5$ & $(5)$ & Informação da aprovação de produto \\
\hline
\end{tabular}




\begin{tabular}{|c|c|c|}
\hline FAIXA & VALOR & REQUISITOS \\
\hline $0-5$ & ( 5 ) & Informação da aprovação de procedimentos \\
\hline $0-5$ & {$[5]$} & Informação da aprovação de processos \\
\hline $0-5$ & $(5)$ & Informação da aprovação de equipamento \\
\hline $0-5$ & {$[5]$} & Informação de qualificação de pessoal \\
\hline $0-5$ & $(0)$ & Informação do SGQ \\
\hline $0-5$ & $(0)$ & Procedimento para inspeção de produtos \\
\hline \multirow[t]{2}{*}{ Total } & 35 & \\
\hline & 45 & Produção e fornecimento de serviço \\
\hline $0-5$ & $(5)$ & Incluir a disponibilidade de informações que descrevem as características do produto \\
\hline $0-5$ & (5) & Incluir a disponibilidade de instrução de trabalho \\
\hline $0-5$ & ( 5 ) & Prover o uso de equipamento adequado \\
\hline $0-5$ & (5) & Prover a disponibilidade e uso de dispositivos para monitoramento e medição \\
\hline $0-5$ & $(5)$ & Implementação de monitoramento e medição \\
\hline $0-5$ & ( 5 ) & Implementação da liberação \\
\hline $0-5$ & ( 5 ) & Implementação da entrega \\
\hline $0-5$ & $(0)$ & Implementação de atividades pós-entrega \\
\hline $0-5$ & ( 5 ) & Procedimento para identificação e rastreabilidade \\
\hline \multirow[t]{2}{*}{ Total } & 40 & \\
\hline & 25 & Controle de dispositivos de medição e monitoramento \\
\hline $0-5$ & ( 5 ] & Os dispositivos devem ser calibrados ou verificados em intervalos específicos antes do uso, contra padrões de medição rastreáveis \\
\hline $0-5$ & $(5)$ & Os dispositivos devem ser ajustados e reajustados como necessários \\
\hline $0-5$ & {$[5]$} & Os dispositivos devem ser identificados para possibilitar que situação da calibração seja determinada \\
\hline $0-5$ & ( 5 ) & Os dispositivos devem ser protegidos contra ajustes que invalidariam o resultado da medição \\
\hline $0-5$ & (5) & Os dispositivos devem ser protegidos de danos e deterioração durante o manuseio, manutenção e armazenamento \\
\hline \multirow[t]{2}{*}{ Total } & 25 & \\
\hline & 20 & Controle de produto não-conforme \\
\hline $0-5$ & $(5)$ & Assegurar a tomada de ações para eliminar a não-conformes detectada \\
\hline $0-5$ & (5) & Assegurar a autorização do seu uso \\
\hline $0-5$ & (5) & Assegurar a autorização de aceitação sob concessão por uma autoridade pertinente e, onde aplicável, pelo cliente \\
\hline $0-5$ & ( 5 ) & Assegurar a tomada da ação para impedir a intenção original de seu uso ou aplicação \\
\hline \multirow[t]{2}{*}{ Total } & 20 & \\
\hline & 20 & Análise de dados \\
\hline $0-5$ & {$[0]$} & Deve-se ter informação da satisfação do cliente \\
\hline $0-5$ & $(5)$ & Deve-se ter informação com os requisitos do produto \\
\hline $0-5$ & ( 0$)^{2}$ & Deve-se ter informação e tendências dos processos e produtos, incluindo oportunidades para ações preventivas \\
\hline $0-5$ & ( 5 ) & Deve-se ter informação dos fornecedores \\
\hline \multirow[t]{2}{*}{ Total } & 10 & \\
\hline & 80 & Medição, análise e melhoria / Monitoramento \\
\hline $0-5$ & $(0)$ & Procedimento para análise crítica das não-conformidades \\
\hline $0-5$ & $(5)$ & Procedimento de determinação das causas das não-conformidades \\
\hline $0-5$ & ( 5 ) & $\begin{array}{l}\text { Procedimento para avaliação da necessidade de ações para assegurar que aquelas não-conformidades não } \\
\text { ocorrerão novamente }\end{array}$ \\
\hline $0-5$ & $(5)$ & Procedimento para determinação e implementação de ações necessárias \\
\hline $0-5$ & ( 5 ) & Procedimento de registro dos resultados de ações executadas \\
\hline $0-5$ & $(0)$ & Procedimento de análise crítica de ações corretivas executadas \\
\hline $0-5$ & ( 0 ) & Procedimento c/ definição de não-conformidades potenciais e de suas causas \\
\hline
\end{tabular}




\begin{tabular}{|c|c|c|}
\hline FAIXA & VALOR & REQUISITOS \\
\hline $0-5$ & ( O ) & Procedimento c/ avaliação da necessidade de ações para prevenir a ocorrência de não-conformidades \\
\hline $0-5$ & ( 5 ) & Procedimento c/ definição e implementação de ações necessárias \\
\hline $0-5$ & ( 5 ) & Procedimento c/ registros de ações executadas \\
\hline $0-5$ & ( 0 ) & Procedimento c/ análise crítica de ações preventivas executadas. \\
\hline $0-5$ & $(0)$ & Melhorar continuamente a eficácia do sistema de gestão da qualidade \\
\hline $0-5$ & $(5)$ & Técnicas estatísticas \\
\hline $0-5$ & $(0)$ & Monitoramento de informações relativas a percepção do cliente \\
\hline $0-5$ & $(5)$ & Auditorias internas com intervalos regulares \\
\hline $0-5$ & $(5)$ & Documentos que demonstrem a conformidade do produto \\
\hline Total & 45 & \\
\hline
\end{tabular}

verifica-se que apenas em um subitem esse requisito obteve o valor 5 (Instituição da política da qualidade). Já o requisito "Política da qualidade" obteve três valores 0 em seus subitens e alcançou a percentagem de implementação de $40 \%$, após a obtenção de dois valores 5 .

Com $73,3 \%$ de percentagem de implementação, o requisito "Responsabilidade, autoridade e comunicação" alcançou três subitens com valor 5 .

"Análise crítica pela alta administração" obteve quatro subitens com valor 5 e sua percentagem de implementação alcançou 50,9\%. Percentagem próxima à alcançada pelos requisitos "Análise de dados" e "Medição, análise e melhoria / Monitoramento", com $50,0 \%$ cada.

Ambos com uma percentagem de implementação de $45 \%$, os requisitos "Provisão de recursos" e "Recursos humanos" obtiveram valor 5 em apenas um subitem.

Observa-se também que o requisito "Processos relacionados aos clientes/foco no cliente" alcançou 83,6\% de percentagem de implementação, enquanto que "Aquisição" e "Produção e fornecimento de serviço" obtiveram $77,8 \%$ e $88,9 \%$, respectivamente.

E por fim, o requisito "Projeto e desenvolvimento de produto / Planejamento da realização do produto" alcançou 72,5\% de percentagem de implementação. É importante observar que, quando esse requisito for analisado para uma empresa que no seu Sistema de Gestão da Qualidade não tiver incluso o requisito "Projeto do Produto", a quantidade de subitens avaliados será apenas oito, que se referem apenas ao planejamento e à realização do produto.

Dividindo-se o total pontuado pelo total possível de obtenção de todos os requisitos, obtém-se a percentagem geral de implementação dos requisitos, que nesse caso ficou em $70,6 \%(385 / 545 * 100)$.
Analisando os resultados obtidos, pode-se observar que alguns requisitos estão na situação de baixa implementação, como "Provisão de recursos", "Recursos humanos" e "Medição análise e melhoria / Monitoramento".

Relacionando esses três requisitos com os requisitos do diagnóstico da Tabela 2, pode-se verificar que estes requisitos referem-se aos seguintes: "Provisão de recursos" - "Gestão de recursos"; "Recursos humanos" "Ambiente de trabalho"; e "Medição, análise e melhoria / Monitoramento" - "Melhoria contínua".

Além disso, é importante verificar que suas respectivas ordenações pela Tabela 2 são: Gestão de recursos 14을 Ambiente de trabalho 15으 e Melhoria contínua - 9o Pode-se considerar que, na ordenação apresentada, eles estão bastante próximos, concluindo-se que podem apresentar um mesmo grau de dificuldade da implementação. Mas, se a implementação ocorrer por etapas, devem ser escolhidos os requisitos mais fáceis de serem implementados para iniciar, como por exemplo "Aquisição" e "Análise de dados".

Os elementos que tiveram baixo percentual de implementação e que pela Tabela 2 são fáceis de serem implementados devem ser mais prioritários, tendo em vista a cultura da empresa, voltada para o ambiente in-line e que seus empregados não são motivados por desafios.

\section{CONCLUSÕES}

A necessidade de sistemas de gestão da qualidade nas empresas é amparada pela exigência de haver uma organização formal para a implementação e manutenção da gestão da qualidade. Assim, o Sistema da Qualidade estrutura a organização necessária para a implementação da gestão da qualidade e deve estar presente em todas as 
fases do ciclo de vida dos produtos e dos processos desde a identificação inicial das necessidades do mercado até a satisfação das exigências dos clientes. Compondo o sistema da qualidade, tem-se a função do controle da qualidade, para executar as atividades necessárias ao planejamento e implementação das ações, e a função da garantia da qualidade, a fim de registrar e manter atualizados os registros de tudo que é feito para a obtenção da qualidade na empresa. necessidades dos stakeholders e com a melhoria contínua, a fim de aumentar a satisfação desses, formando uma reputação pelo tipo e qualidade do serviço que oferecem e produzem.

Diante disso, observa-se que os esforços pela qualidade e pela certificação nas normas ISO 9000 afeta de forma positiva a melhoria contínua da empresa, sendo evidenciados principalmente na competitividade da empresa e na satisfação dos stakeholders (MILOSEVIC \& PATANAKUL, 2005).

Esse trabalho teve o objetivo de desenvolver uma ferramenta que auxilie as empresas no processo de implementação do Sistema de Gestão da Qualidade baseado nos requisitos da Norma ISO 9001:2000. Assim, empresas certificadas pelas antigas Normas da Série ISO 9000 podem fazer a transição sem muitas dificuldades, e empresas que estão sem certificação

Acredita-se que a implantação dos requisitos da norma ISO 9000 enquadra-se perfeitamente de modo a satisfazer essa necessidade de uma organização formal. Além disso, a aplicação eficaz desses requisitos com o seu acompanhamento e melhoramento constantes incentiva a competitividade da empresa, proporcionando facilidades para que a organização obtenha diferenciação no mercado, assim como melhor nível de serviço oferecido. Já que aplicação dos requisitos itens da norma ISO 9001:2000 influencia, de forma positiva para a empresa, seu poder competitivo face às cinco principais forças competitivas de Porter (1999): ameaça de empresas ingressantes, ameaça de produtos ou serviços substitutos, poder de barganha de fornecedores, poder de barganha de consumidores e rivalidade entre as empresas existentes.

Crê-se que a diferenciação do serviço é conseguida pela aplicação dos requisitos da norma ISO 9001, através de sua constante preocupação com o atendimento às podem obtê-la mais facilmente.

Em se tratando de empresas de pequeno porte, esse diagnóstico pode auxiliar no direcionamento de seus recursos para os requisitos que são prioritários e, assim, iniciar por aqueles mais fáceis, para aprender e ter experiência a fim de passar para os mais difíceis.

Acredita-se que, com o modelo apresentado neste trabalho, seja possível quantificar o nível de implementação do Sistema de Gestão da Qualidade. Porém, esse primeiro diagnóstico apenas informa percentualmente o grau de implementação dos itens, devendo-se utilizar o modelo comparativo para uma melhor avaliação. Dessa forma, a avaliação para implementação do Sistema de Garantia da Qualidade da empresa seria bastante satisfatória.

Espera-se que o modelo proposto para a implementação do SGQ, baseado nos requisitos da norma ISO 9001:2000, possa ser aplicado a organizações que queiram buscar um melhor desempenho na qualidade do seu produto.
Artigo recebido em 05/05/2005

Aprovado para publicação em 07/12/2005 


\section{- Referências Bibliográficas}

ABNT, Associação Brasileira de Normas Técnicas. NBR ISO 9000: 2000 Sistema de gestão da qualidade - Fundamentos e vocabulário. Rio de Janeiro: ABNT, 2000

NBR ISO 9001: 2000 - Sistema de gestão da qualidade - Requisitos. Rio de Janeiro: ABNT, 2000

NBR ISO

9004: 2000 - Sistema de gestão da qualidade - Diretrizes para melhorias de desempenho. Rio de Janeiro: ABNT, 2000.

BARROS, A. J. P.; LEHFELD, N. A. S. Projeto de pesquisa: propostas metodológicas. Petrópolis: Vozes, 1990.
BRANSKY, J. R. Raising the credibility of thirdy-party certification to ISO 9001:2000. ISO Management Systems, Viewpoint, v. 18, NovemberDecember, 2004.

CHAN, K. C. C. Costs and benefits of ISO 9000 series: a practical study. International Journal of Quality \& Reliability Management, v. 16, n. 7, 1999.

CHAN, K. C. C. Improving quality management on the basis of ISO 9000. The TQM Magazine. v. 11 , Issue 2, 1999.

DE MEDEIROS, D. D. Diagnóstico e análise de sistemas da qualidade: um modelo para avaliação e preparação dos sistemas para a certificação ISO 9000. Revista Produção - Rio de Janeiro, v. 9, n. 2, p. 49-63, 2000
LASZLO, G. ISO 9000 or TQM: Which approach to adopt - A Canadian study. The TQM Magazine, v. 10, Issue 10, 1998.

LEONARD D. \& MCADAM, R. Quality's six life cycle stages. Quality Progress. ABI/INFORM Global, v. 36, n. 8; p. 50, Aug, 2003

MILOSEVIC, D. \& PATANAKUL, P. Standardized project management may increase development projects success International Journal of Project Management, v. 23, Issue 3, 1, pages 181-192, April 2005

PALADINI, E. P. Avaliação Estratégica da Qualidade. São Paulo: Atlas, 2002 .
PORTER, M. E. Competitive Advantage: Creating and Sustaining Superior Performance. Free Press, New York, 1999.

QUAZI, H. A. Journey Towards Tota Quality Management through ISO 9000 Certification - A Singapore experience. The TQM Magazine, v. 9 Issue 5, 1997.

RODRIGUES, M. V. C. Ações para a Qualidade: GEIQ Gestão Integrada para a Qualidade - Padrão Seis Sigma - Classe Mundial. Rio de Janeiro: Qualitymark, 2004.

SMITH, T. The Future of Management System Standards. ISO Management Systems. Viewpoint. v. 6, NovemberDecember, 2002.

\section{- Sobre os autores}

Luís Cláudio da Conceição Correia

Grupo de Pesquisa PLANASP - Departamento de Engenharia de Produção

Universidade Federal de Pernambuco

Endereço: Rua Acadêmico Hélio Ramos, s/n - CEP 50740-530 - Recife - PE

E-mail: planasp@ufpe.br

\section{Maria Auxiliadora do Nascimento Mélo}

Grupo de Pesquisa PLANASP - Departamento de Engenharia de Produção

Universidade Federal de Pernambuco

Endereço: Rua Acadêmico Hélio Ramos, s/n - CEP 50740-530 - Recife - PE

E-mail:manmelo@ufpe.br

\section{Denise Dumke de Medeiros}

Grupo de Pesquisa PLANASP - Departamento de Engenharia de Produção

Universidade Federal de Pernambuco

Endereço: Rua Acadêmico Hélio Ramos, s/n - CEP 50740-530 - Recife - PE

E-mail:ddm@ufpe.br 